\title{
Patients with negative multi-gene panel testing: a back to the future paradox?
}

\author{
Steven M. Sorscher ${ }^{1}$
}

Published online: 3 March 2017

(C) Springer Science+Business Media Dordrecht 2017

To the Editor,

Recently in Familial Cancer, Hermel et al. reported that multi-gene panel testing for hereditary cancer susceptibility "changed cancer screening and management guidelines from that expected based on family history alone in $13.2 \%$ of patients" [1]. Patients often seek testing for reassurance that family members carry no predisposing genes. Could the patients who tested negative be offered that reassurance? Were management recommendations changed for those patients?

Multi-gene panel testing has allowed the identification of germline deleterious mutations responsible for more than $90 \%$ of the familial breast cancer syndromes and is now offered patients who are either young at diagnosis, have a strong family history, or both. However, current guidelines recommend that once a patient tests negative (and another affected family member also tests negative) future screening and prophylactic treatments should still be based on the personal and family history, just as it was years ago before we had multi-gene panel testing to offer patients [2].

The basis for this apparent paradox is that the elimination by multi-gene panel testing for the common cancer predisposing genes has not been shown to appreciably change the risk of a germline mutation (as yet not part of the panel) having been inherited by a particular patient. That likelihood remains related to the personal and family history (i.e. whether the patient meets the clinical criteria for being part of a family with a hereditary breast cancer syndrome).

It is important that cancer patient providers make clear to patients that, in spite of the enormous advances in identifying cancer predisposing genes, a negative multi-gene panel testing result does not appear to change their likelihood of harboring an altered predisposing gene or combination of genes. One predictable danger of multi-gene panel testing is that clinicians will forget that personal and family history remain the standard tool for predicting risk.

Funding There was no research support.

Compliance with ethical standards

Conflict of interest I have no relevant conflict of interest.

\section{References}

1. Hermel DJ, McKinnon WC, Wood ME et al (2016) Multi-panel testing for hereditary cancer suseptibility in a rural familial cancer program. Fam Cancer. doi:10.1007/s10689-016-9913-5

2. Daly MB, Pilarski R, Axilibund JE et al (2016) Genetic/familial high-risk assessment: breast and ovarian NCCN guideline version 1.2016. J Natl Compr Canc Netw 14:153-162
Steven M. Sorscher

ssorsche@wakehealth.edu

1 Oncology Division, Wake Forest Medical School, Winston-Salem, NC 27154, USA 